\title{
Prevalence of cricket-related musculoskeletal pain among adolescent cricketers in KwaZulu-Natal
}

\author{
M H Noorbhai (BSps (Hons) Biokinetics) \\ F M Essack (BSps (Hons) Biokinetics) \\ S N Thwala (BSps (Hons) Biokinetics) \\ $\mathrm{T} J$ Ellapen $(\mathrm{PhD})$ \\ $\mathrm{J} H$ van Heerden (DPhil) \\ Department of Sport Science, School of Physiotherapy, Sport Science and Optometry, University of KwaZulu-Natal \\ Correspondence to: Habib Noorbhai (habib.noorbhai@yahoo.com)
}

\begin{abstract}
Objectives. This study investigated the prevalence and nature of cricket-related musculoskeletal pain among male adolescent cricket players $(n=234)$ residing in the Highway area of Durban over a 12-month period during all the seasons of the year.

Methods. Data were collected from five secondary schools. Subjects' participation was dependent on voluntary and parental informed consent. Child assent forms were also provided for the schoolboy cricket players to complete. Participants were required to complete a self-reported questionnaire probing the prevalence of musculoskeletal pain within the last 12 months. The probability was set at $\mathrm{p} \leq 0.05$.

Results. A total of 188 subjects (80\%) experienced cricket-related musculoskeletal pain $(\mathrm{p}<0.0001)$. The most common sites were the lower extremities (39\%), followed by upper extremities (36\%) and lower back (18\%). The prevalence of cricket-related musculoskeletal pain specific to the various anatomical sites were mostly knee (30\%) and lower back (29\%), followed by shoulder (17\%), ankle (13\%) and thigh (11\%). The predisposing mechanisms producing cricket-related musculoskeletal pain reported by the cricketers were direct physical trauma (83\%) and over-use $(17 \%)(\mathrm{p}<0.0001)$. Conclusion. Male adolescent recreational cricket players reported a high prevalence of cricket-related musculoskeletal pain. The knee was the most common anatomical site. Parents, guardians and coaches should pay specific caution to preliminary and extrinsic factors causing musculoskeletal pain in adolescent cricketers.
\end{abstract}

\section{Introduction}

Cricket is a dynamic sport that involves many abstract skills and movements. To enhance these skills and movements, many players ensure that their bodies are kept fit and strong..$^{1-3}$ There are three unique aspects of the game (bowling, batting and fielding) which are associated with risk of injury. ${ }^{2,3}$ Currently the male South African cricket team is ranked 3rd in test cricket, $3 \mathrm{rd}$ in one-day international cricket and 4th in T20 cricket (as of 06/01/2011). ${ }^{4}$ To possess such a strong national side, the building blocks and foundations have to be laid at school level to meet the required standards when schoolboy cricket players develop and transcend to provincial and national levels. ${ }^{5}$

Musculoskeletal pain can occur in various ways while playing cricket: a player being struck by a ball or bat, rapid rotational movements, sliding and diving, collisions with other players and over-

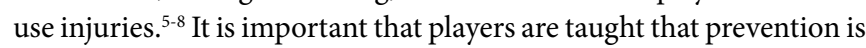

better than cure. ${ }^{9}$ Some players do not have adequate physical training, and are therefore not physically prepared for cricket. ${ }^{10}$ Because of this, their muscle strength, endurance, agility and fitness on the field may not always be adequate for the game of cricket. $^{3}$

International cricket studies mostly concentrate on young fastbowlers and their injuries. ${ }^{11,12}$ Dennis et al. focused on bowling workloads regarding injury rates in young fast-bowlers. ${ }^{11}$ Hardcastle et al. focused on spinal abnormalities in young fast-bowlers. ${ }^{12} \mathrm{~A}$ number of studies conducted in South Africa identified a prevalence of cricket-related musculoskeletal injuries among elite cricketers. ${ }^{1,6,8}$ These studies found that the most common anatomical sites of injury were lower limb, followed by upper limb and lower back. ${ }^{5}$ Stretch et al. reported that the lower limbs (50\%), upper limbs (23\%), and back and trunk (23\%) were most commonly injured in South African cricketers. ${ }^{5}$ Milsom et al. reported that in South African schoolboy cricketers $34 \%$ of injuries were sustained to the upper limbs, $34 \%$ to the lower limbs and $31 \%$ to the back and trunk. ${ }^{7}$

To the best of the researchers' knowledge, no studies have investigated injuries and pain among schoolboy cricket players in specific geographical regions within South Africa. The aim of this study was to document cricket-related musculoskeletal pain among schoolboy cricket players in KwaZulu-Natal.

\section{Methods}

This was a retrospective study which documented cricket-related musculoskeletal pain over a 12-month period and employed both qualitative and quantitative designs. Subjects were adolescent male recreational cricketers who participated voluntarily after their parents had given their informed consent. Child assent forms were provided for the schoolboy cricket players to complete. The subjects $(n=234)$ were recruited from five (5) secondary schools in KwaZulu-Natal: Glenwood High, Kloof High School, Durban High School, Westville Boys High and Pinetown Boys High School. These schools were chosen because they were considered to be among the top cricketing schools, according to the KwaZulu-Natal Cricket Union. The players' ages ranged from 14 to 17 years. The identity of all the subjects was kept anonymous and confidential. Ethical clearance for the study was obtained from the Research Committee of the Faculty of Health Sciences at the University of KwaZulu-Natal-Westville. Reasons for recruiting male subjects are as follows:

- The participation rate in cricket is greater among males than females.

- A homogenous male cohort allows for findings to be more reliable.

Therefore, inclusion of females into the cohort would have increased 
the unreliability of the findings due to physiological and hormonal differences.

Data were collected through a self-reported musculoskeletal questionnaire (adapted from Ellapen et al. ${ }^{13}$ ) to determine the prevalence of pain at various anatomical sites. The questionnaire (see appendix) and the relevant documentation were explained thoroughly to all subjects, to reduce recall bias. This study employed the following definition of musculoskeletal pain: 'A sensation of agony that inhibits the individual from participating in cricket or practice for a minimum of twentyfour hours. ${ }^{14}$ Attempts to document the prevalence of musculoskeletal injury would be unreliable in the absence of medical certification. The researchers doubted that all the subjects would have kept medical records of their injuries within the previous 12 months and so, in the absence of medical records, identification of musculoskeletal pain via subject recall was deemed to be more reliable. Subjects' identification of musculoskeletal pain, types of pain, intensity of pain (according to the Borg CR10 scale) and anatomical location of pain were recorded to infer musculoskeletal injury. ${ }^{15,16}$

Injury rates were calculated according to a numerator variable (number of injuries sustained) linked to a denominator variable (number of hours played over the last 12 months), giving the number of injuries sustained for every hour played over the last 12 months. Body mass and stature of all the subjects were measured according to the Houglum protocol. ${ }^{17}$ The data were analysed descriptively (mean, mode, frequency and percentages) and inferentially (chi-square test). The level of significance was set at $\mathrm{p} \leq 0.05$.

\section{Results}

Results demonstrated the epidemiology of pain, prevalence of pain, nature of pain and training factors.

Demographic and physical characteristics are reported in Table 1. Results showed that 188 subjects experienced cricket-related musculoskeletal pain (Table 2). The predisposing mechanisms producing the pain were direct physical macrotrauma $(83 \%)$ and microtrauma (17\%). Macrotrauma is a force produced by a single incident which causes an acute injury whereas microtrauma is a repetitive or chronic injury which lasts over a period of time. ${ }^{18}$ These types of injuries relate to the injuries sustained by the cohort in the study. The anatomical sites of cricket-related musculoskeletal pain were knee $(30 \%)$, lower back (29\%), shoulder (17\%), ankle (13\%) and thigh $(11 \%)(\mathrm{p}<0.0001)$ (Fig. 1). Amongst the cohort, $30 \%$ of batsmen, $28 \%$ of all-rounders, $23 \%$ of bowlers and $7 \%$ of wicket-keepers were investigated for pain $(\mathrm{p}<0.0001)$.

The types of pain experienced by the subjects were mostly discomfort (39\%), dull aching pain (32\%), spasms (19\%), sharp pain (19\%) and swelling (17\%) (Table 3). The intensity of pain experienced by the subjects was moderate $(34 \%)$, low $(26 \%)$, uncomfortable (17\%), high (13\%) and severe (4\%).The subjects' duration of pain was indicated as follows: few hours (30\%), few days (28\%), unpredictable $(25 \%)$ and continuous (17\%).

Table 1. Demographical and physical characteristics of sample $(n=234)$

$\begin{array}{ll}\text { Variables } & \text { Mean } \pm \text { SD } \\ \text { Age (years) } & 15.6 \pm 1.1 \\ \text { Body weight }(\mathrm{kg}) & 69.2 \pm 13.5 \\ \text { Stature }(\mathrm{m}) & 1.71 \pm 0.15 \\ \text { Body Mass Index }\left(\mathrm{kg} / \mathrm{m}^{2}\right) & 20.8 \pm 11.7\end{array}$

Table 2. Prevalence of musculoskeletal pain among cricket players $(n=188)$

$\begin{array}{ll}\text { Role } & \text { Presence of pain (\%) } \\ \text { Batsmen } & 30 \\ \text { Bowlers } & 23 \\ \text { All-rounders } & 28 \\ \text { Wicket-keepers } & 7\end{array}$

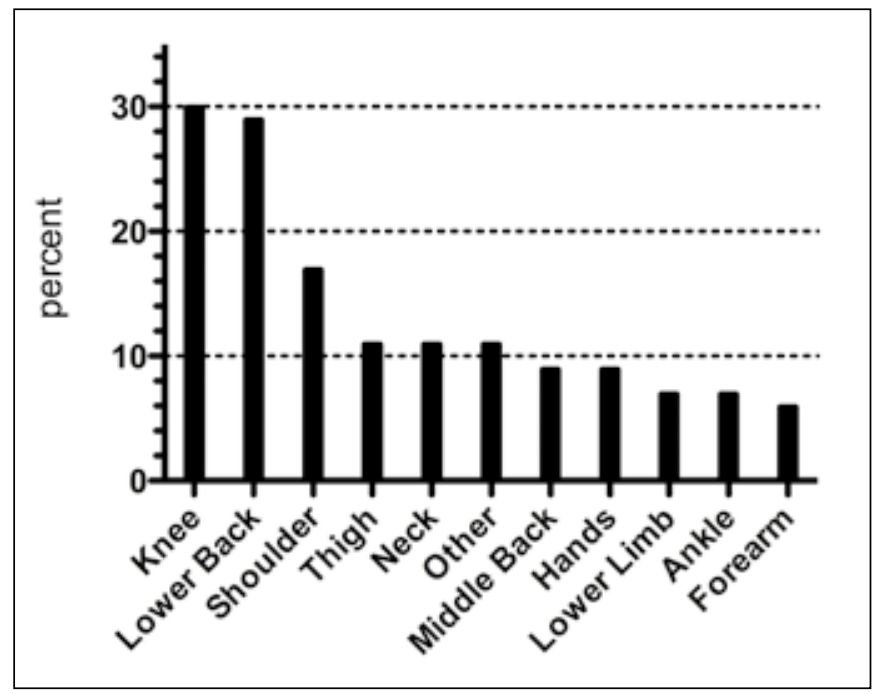

Fig. 1. Prevalence of cricket-related musculoskeletal pain at specific anatomical sites $(\mathrm{n}=188)(\mathrm{p}<0.0001)$.(Other $=$ hip, jaw and mouth. $)$

The average training history amongst the cohort was: 7.6 months in a year practised, 2.9 days a week practised and 126 minutes per training session (Table 4). The types of training performed across the cohort were skills (25\%), coordination (18\%), agility training (14\%), core stability (14\%), aerobic training (11\%), weight training (10\%) and flexibility training $(8 \%)$.

Table 3. Types of pain, intensity of pain and duration of pain among cricket players $(n=188)$

$\begin{array}{llllll}\text { Types of pain } & \% & \text { Intensity of pain } & \text { D } & \text { Duration of pain \% } \\ \text { Discomfort } & 39 & \text { Moderate } & 34 & \text { Few hours } & 30 \\ \text { Dull aching } & 32 & \text { Low } & 26 & \text { Few days } & 28 \\ \text { Spasms } & 19 & \text { Uncomfortable } & 17 & \text { Unpredictable } & 25 \\ \text { Sharp } & 19 & \text { High } & 13 & \text { Continuous } & 17 \\ \text { Swelling } & 17 & \text { Severe } & 4 & & \end{array}$

\section{Discussion}

Of the 234 cricket players investigated, 188 (80\%) experienced cricket-related musculoskeletal pain within the last 12 months $(p<0.0001)$. These findings support other international and local studies on cricket-related musculoskeletal pain/injury. ${ }^{1,5-8,11,12}$ The anatomical sites of the pain were knee (30\%), lower back $(29 \%)$, shoulder $(17 \%)$, ankle $(13 \%)$ and thigh $(11 \%)(\mathrm{p}<0.0001)$. The most common anatomical sites were lower extremities $(39 \%)$, followed by upper extremities (36\%) and lower back (18\%). These results are consistent with other findings. ${ }^{5,7}$ Stretch et al. reported that the lower limbs (50\%), upper limbs (23\%), and back and trunk (23\%) were 
Table 4. Training history reported by subjects within the last 12 months $(n=234)$

\begin{tabular}{ll}
\hline Variables & Mean \pm SD \\
Months/year & $7.6 \pm 2.7$ \\
Days/week & $2.9 \pm 1.2$ \\
Minutes/training session & $126 \pm 22$
\end{tabular}

most commonly injured in South African cricketers. ${ }^{5}$ Milsom et al. reported that in South African schoolboy cricketers 34\% of injuries were sustained to the upper limbs, $34 \%$ to the lower limbs and $31 \%$ to the back and trunk.?

The types of pain experienced by the subjects were discomfort (39\%), dull aching pain (32\%), spasms (19\%), sharp pain (19\%) and swelling (17\%). Dull aching and discomfort pain sensations are associated with muscle pain, whereas pins and needles and radial pain sensations are associated with neurological pathologies. ${ }^{9,17,19}$ In most cases the pain was musculoskeletal and not neurological. The duration of pain was indicated as follows: few hours (30\%), few days (28\%), unpredictable (25\%) and continuous (17\%). Subjects experiencing continuous pain and unpredictable pain were associated with microtraumas. Similarly, subjects experiencing pain within a few hours, few days or an unpredictable duration were associated with macrotraumas. The nature of pain (anatomical location of pain, types of pain, intensity of pain and duration of pain) in this study clearly indicates musculoskeletal pain pathologies, thus demonstrating the prevalence of cricket-related musculoskeletal pain.

Amongst the cohort, $30 \%$ of batsmen, $28 \%$ of all-rounders, $23 \%$ of bowlers and $7 \%$ of wicket-keepers were investigated for pain. These findings conflict with previous studies on schoolboy cricketers, where injuries to bowlers (47\%) were found to be higher than in batsmen (30\%) and fielders (23\%). ${ }^{8}$ Milsom et al. reported that bowling accounted for $51 \%$ of the injuries, while fielding accounted for $33 \%$, batting for $15 \%$ and the remaining injures occurred while warming up or training. ${ }^{7}$ The differences in the above findings could be due to the different types of players participating in the study (batsmen, bowlers, fielders and wicket-keepers) and the different types of injuries sustained. An injury was defined as any physical damage that occurred during a match, practice or training session and which prevented the player from completing the match, practice or training session. These studies also included a few differences in the questionnaires where it focused on detailed times of the year for incidences in injuries and whether the injuries were recurrent or recent.

The lower back and knee are mostly associated with microtrauma injuries. ${ }^{9}$ Fast-bowling is associated with a high risk of lower back pain. Lumbar pain, which is common among fast-bowlers, can lead to premature retirement of these players. ${ }^{12}$ This is also due to the forceful release by fast-bowlers at the popping crease of the pitch, causing the bowlers to hyperextend their backs. ${ }^{10,11}$ Similarly, spin-bowlers experience lower back pain due to the pivot and lateral rotation of the hips after the ball has been released, causing the abdominal and oblique muscles to compensate for these movements. ${ }^{10,11}$ Subjects who experienced knee pain were mostly batsmen and wicket-keepers. Batsmen display movements either on the front foot (propelling forward) or back foot (propelling backwards) and these movements load pressure and tension on the knee and surrounding joints of the patella during flexion and extension, placing the knee joint at increased risk. ${ }^{10,19}$ Similarly, wicket-keepers spend most of the time kneeling down and flexing their knees while playing, which also increases their risk of pain at the knee joint. ${ }^{10}$

It was evident that players who did not do sufficient amounts of strength training $(10 \%)$ and flexibility training $(8 \%)(p<0.0001)$ were more predisposed to musculoskeletal pain or injury. Strength training has its benefits: an individual will become more resistant to pain or injury and can overcome pain much easier because of increased strength. ${ }^{9,10,19}$ Safe strength training at this point in a cricketer's development enhances resilience in bones, tendons, ligaments and muscles, resulting in better performance and fewer injuries. ${ }^{10,20}$ Therefore more strength and flexibility training can be initiated to reduce the chances of injury and pain. However, caution should be adopted with adolescent cricketers, as their epiphyseal plates can be hindered with strength training. ${ }^{9}$ For males, 12 - 18 months after their growth spurt is the ideal time to start strength and flexibility training..$^{9,20}$

The average training history amongst the cohort was: 7.6 months' practice in a year, 2.9 days' practice a week and 126 minutes per training session. Subjects experienced an injury rate of 0.2 injuries for every playing hour over the previous 12 months. As adolescent cricketers and young athletes, 4 days per week of training and matches are optimal, whereas 2 - 3 days per week are minimal. ${ }^{9,11}$ Regarding bowlers, important research was done by Dennis et al., who noted that bowlers with an average of less than 3.5 rest days were at a significantly increased rate of injury and that there was also an increased risk of injury for those who bowled an average of more than 2.5 days a week. ${ }^{13}$ Considering this research, more attention should be placed on bowlers with regard to sufficient rest days to reduce injury rates. Although 117 (62\%) subjects participated in other additional activities and sport in the cricket off-season, in all cases their musculoskeletal pain was cricket-related.

A recommendation from this study is that cricket coaches should be cautious when training players with existing pain. It is advisable for coaches to utilise logbooks during training sessions to keep record of the number of hours, weeks and months trained by each player so that potential overuse injuries or recurrent pain can be minimised. ${ }^{10}$ Coaches should also ensure that the technical errors of the players are corrected. ${ }^{10}$ Furthermore, coaches need to be educated on the prevalence of pain and injuries that occur in cricket players, the correct techniques in cricket and how to assist schoolboy cricketers in adapting their technique to avoid potential pain and injuries.

\section{Conclusion}

This study showed that male adolescent recreational cricket players residing in the Highway area of KwaZulu-Natal sustained a high prevalence of musculoskeletal pain. The intrinsic factors (direct physical traumas and overuse) were the main contributors to the subjects experiencing pain. The knee was the most prevalent anatomical site of cricket-related musculoskeletal pain. It is essential that a database for male adolescent cricket players in KwaZuluNatal be implemented. Further longitudinal investigations should be conducted among male adolescent cricket players residing in other regions in all South Africa.

\section{Acknowledgements}

The authors would like to extend their appreciation and gratitude to the Cricket High Schools of KwaZulu-Natal, Dr MA Noorbhai, Dr AK Halabi, Mrs KB Halabi and Ms S Abrahams for their assistance during the study. 


\section{REFERENCES}

1. Aginsky KD, Lategan L, Stretch RA. Shoulder injuries in provincial male fast bowlers - predisposing factors. S Afr J Sports Med 2004;16(1):25-28.

2. Myers P, O'Brien S. Cricket: Injuries, Rehabilitation and Training. London: Lippincott Williams \& Wilkins, 2001:124-136.

3. Petersen CJ, Pyne DB, Dawson BT, Kellet AD, Portus MR. Comparison training and game demands of national level cricketers. J Strength Cond Res 2011;25(5):13061311.

4. http://icc-cricket.yahoo.com.net/match_zone/team_ranking.php (accessed 6 January 2011).

5. Stretch RA. Cricket injuries: a longitudinal study of the nature of injuries to South African cricketers. Br J Sports Med 2003;37:250-253.

6. Giles K, Musa I. A survey of glenohumeral joint rotational range and non-specific shoulder pain in elite cricketers. PhysTher Sport 2008;9(3):109-116.

7. Milsom NM. Barnard JG, Stretch RA. Seasonal incidence and nature of cricket injuries among elite South African schoolboy cricketers. S Afr J Sports Med 2007;19(3):80-84

8. Stretch RA. The incidence and nature of injuries in schoolboy cricketers. S Afr Med J 1995;85:1182-1184.

9. Brukner P, Khan K. Clinical Sports Medicine, revised 3rd ed. New York: The McGraw Hill Company, 2009:27-105.

10. Woolmer B, Noakes TD, Moffett H. Bob Woolmer's Art and Science of Cricket. Cape Town: Struik Publishers, 2009:86-322, 464-520, 526-630.
11. Dennis RJ, Finch CF, Farhart PJ. Is bowling workload a risk factor for injury to Australian junior cricket fast bowlers? Br J Sports Med 2005;39:843-846.

12. Hardcastle P. Spinal abnormalities in young fast bowlers. Aust N Z J Surg 1992;74B(3):421-425

13. Ellapen TJ, Demartinis R, Hughes T, Hansen C, Van Heerden HJ. The incidence of hockey ankle injuries in KwaZulu-Natal. Research report, University of KwaZuluNatal. AJPHERD 2009;15(3):417-423.

14. Van Heerden HJ. Pre-participation evaluation and identification of aetiological risk factors in epidemiology of sports injuries among youths. Thesis: Doctor of Philosophy Pretoria: University of Pretoria, 1996

15. Fuller CW, Ekstrand J, Junge A. Consensus statement on injury definitions and dat collection procedures in studies of football (soccer) injuries. Scand J Med Sci Sports 2006;16(2):82-83.

16. Hagglund $M$, Walden $M$, Ekstrand J. UEFA Champions League study: a prospective study of injuries in professional football during the 2001-2002 season. Br J Sports Med 2005;39:542-546.

17. Houglum PA. Therapeutic Exercise for Musculoskeletal Injuries, 3rd ed. Champaign, IL: Human Kinetics, 2010:199-254

18. http://www.answers.com/topic/macrotrauma (accessed 6 January 2012).

19. Prentice WE. Rehabilitation Techniques for Sports Medicine and Athletic Training, 5th ed. New York: The McGraw Hill Company 2011:47-92.

20. http://www.pitchvision.com/when-to-introduce-strength-and-endurance-trainingto-young-cricketers (accessed 27 January 2012).

\section{APPENDIX}

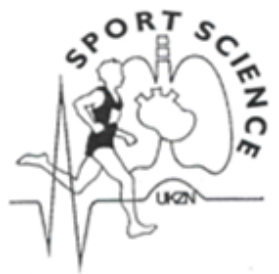

UNIVERSITY OF KWAZULU-NATAL

FACULTY OF HEALTH SCIENCE

SCHOOL OF PHYSIOTHERAPY, OPTOMETRY \& SPORTS SCIENCE

DISCIPLINE OF SPORTS SCIENCE

An epidemiological investigation into the prevalence and aetiology of cricket-related musculoskeletal pain among adolescent cricketers in KZN.

PERSONAL INFORMATION:

Surname:

Name:

Age:

Telephone No: (H)

(CeII)

Gender: Male

Female

Race: African

White

Indian

Coloured

Asian

Body Mass

Stature:

$\mathrm{BMI}:$

What position do you play? 
How long have you been playing at a school/junior provincial level:

\begin{tabular}{|l|l|l|}
\hline Angles & & \\
\hline Shoulder internal rotation & & \\
\hline Shoulder external rotation & & \\
\hline Cubitus angle & & \\
\hline Ulnar deviation & & \\
\hline Q-angle & & \\
\hline
\end{tabular}

\section{TRAINING HISTORY}

1. How many months in a year do you practise?

\begin{tabular}{|l|l|l|l|l|l|}
\hline 1 & 2 & 3 & 4 & 5 & 6 \\
\hline 7 & 8 & 9 & 10 & 11 & 12 \\
\hline
\end{tabular}

2. How many times a week do you have cricket practice?

\begin{tabular}{|c|c|c|c|c|}
\hline 1 & 2 & 3 & 4 & 5 \\
\hline 6 & 7 & 8 & 9 & 10 \\
\hline
\end{tabular}

3. Duration of training per session:

\begin{tabular}{|c|c|c|c|c|}
\hline $1 \mathrm{hr}$ & $2 \mathrm{hrs}$ & $3 \mathrm{hrs}$ & $4 \mathrm{hrs}$ & $5 \mathrm{hrs}$ \\
\hline Other & \multicolumn{3}{|c|}{} \\
\hline
\end{tabular}

4. Do you practise / participate in any additional activities beside cricket?

\begin{tabular}{|c|c|c|c|}
\hline Gym & Swimming & Cricket & Rugby \\
\hline Others & \multicolumn{3}{|c|}{} \\
\hline
\end{tabular}

5. If so, how many times a week:

\begin{tabular}{|c|c|c|c|c|}
\hline 1 & 2 & 3 & 4 & 5 \\
\hline 6 & 7 & 8 & 9 & 10 \\
\hline
\end{tabular}

6. What type of training do you perform?

\begin{tabular}{|c|c|l|c|c|}
\hline Weight Training & Aerobic & Flexibility & Agility & Core Stability \\
\hline Skills & Co-ordination & Other: \\
\hline
\end{tabular}

7. Can you rate your perceived rate of exertion (intensity) when you exercise from 1-20 (Borg Scale) 


\section{EPIDEMIOLOGY}

8. Have you sustained an injury/pain in the last 12 months while playing cricket? Yes $\square$

(Definition of musculoskeletal pain/injury is a sensation of agony that inhibited you from participating in cricket or practice for a minimum of 24 hours).

If yes, explain how the injury/pain occurred:

\begin{tabular}{|l|l|l|l|l|}
\hline $\begin{array}{c}\text { Collision with other } \\
\text { players }\end{array}$ & Struck by the ball & Struck by the bat & $\begin{array}{c}\text { Rapid Rotational } \\
\text { Movement }\end{array}$ & Over-use \\
\hline Other: & & \\
\hline
\end{tabular}

9. Have you experienced musculoskeletal pain/injury in the last 12 months? $\quad$ Yes $\square \quad \square \quad$ No $\square$

10. Where do you experience the symptoms of the pain/injury?

$\begin{array}{ll}\square \text { a) } & \text { Neck } \\ \square \text { b) } & \text { Shoulder } \\ \square \text { c) } & \text { Elbow } \\ \square \text { d) } & \text { Forearm } \\ \square \text { e) } & \text { Hand } \\ \square \text { f) } & \text { Middle back } \\ \square \text { g) } & \text { Lower back } \\ \square \text { h) } & \text { Buttock } \\ \square \text { i) } & \text { Thigh } \\ \square \text { j) } & \text { Knee } \\ \square \text { k) } & \text { Lower limb } \\ \square \text { l) } & \text { Ankle } \\ \square \text { m) } & \text { Foot } \\ \square \text { n) } & \text { Other: }\end{array}$

11. What type symptoms have you experienced?

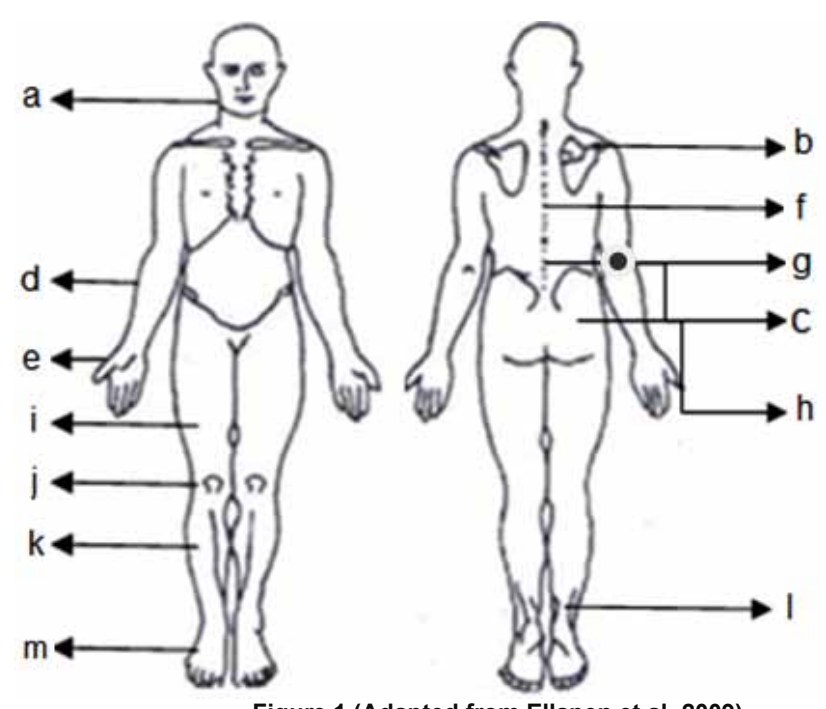

Figure 1 (Adapted from Ellapen et al, 2009)

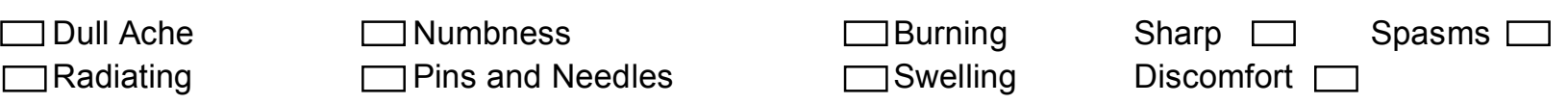

12. How often did you experience the above mentioned pain symptoms in the past 12 months?

a) Once or a few times in the day

b) Every few days

$\square$ c) Once a month

d) Other:

13. How long did the musculoskeletal pain/injury prevent you from participating in cricket practice?

\begin{tabular}{|c|c|c|c|c|c|}
\hline 1 day & 2 days & 3 days & 4 days & 5 days & $\begin{array}{c}\text { More than } \\
5 \text { days }\end{array}$ \\
\hline
\end{tabular}


14. How would you rate the intensity of the symptom you experienced?

\begin{tabular}{|c|c|c|c|c|}
\hline 1 & 2 & 3 & 4 & 5 \\
\hline Uncomfortable & Low & Moderate & High & Severe \\
\hline
\end{tabular}

15. How long did your pain/injury persist for?

$\square$ a) A few hours

b) A few days

$\square$ c) It is continuous

$\square$ d) It is unpredictable

16. Have you obtained the services of any of the following healthcare professionals for your musculoskeletal symptoms?

$\square$ a) Orthopaedic Surgeon

$\square$ b) General Practitioner

$\square$ c) Physiotherapist

$\square$ d) Chiropractor

$\square$ e) Biokineticist

$\square$ f) Massage Therapist

g) Other:

17. Do you play through the pain/injury? Yes $\square \quad$ No $\square$

As a result of this action, does the musculoskeletal pain index increase? Yes $\square \quad$ No $\square$

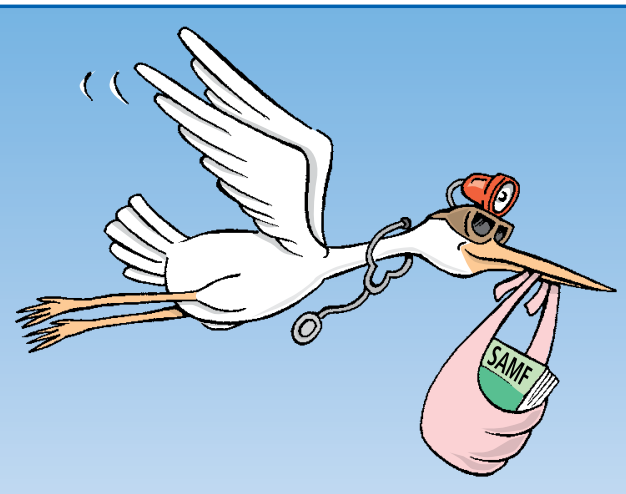

To order your copy of the

updated 2012 edition of the

South African Medicines Formulary, contact Edward or Byron -

tel: 0216817000 or fax: 0866006218

SAMF $20 \hat{\mathrm{i}} 2$ has arrived 